\title{
Mortality from Cancer among US Hemodialysis Patients, 1995-2005
}

\author{
Robert N. Foley ${ }^{a} b$ Tricia L. Roberts ${ }^{a}$ Jiannong Liu ${ }^{a}$ David T. Gilbertson ${ }^{a}$ \\ Thomas J. Arneson ${ }^{a}$ Stephan Dunning ${ }^{a}$ Allan J. Collins ${ }^{a, b}$ \\ ${ }^{a}$ Chronic Disease Research Group, Minneapolis Medical Research Foundation, and ${ }^{\mathrm{b}}$ Department of Medicine, \\ University of Minnesota, Minneapolis, Minn., USA
}

\section{Key Words}

Cancer - Erythropoiesis-stimulating agent $\cdot$ Hemodialysis • Mortality

\begin{abstract}
Background/Aims: Concern has emerged that erythropoiesis-stimulating agents (ESAs) may decrease survival for cancer patients; many patients beginning dialysis have previous cancer diagnoses. As ESA doses have more than tripled in the USA since ESAs were introduced, we aimed to compare annual trends in cancer-specific mortality rates among incident maintenance hemodialysis patients. Methods: This national, retrospective, incident cohort study included 873,493 patients aged $\geq 20$ years who initiated hemodialysis between 1995 and 2005. Cancer-specific mortality rates were adjusted for baseline characteristics, determined from the Centers for Medicare \& Medicaid Services (CMS) Medical Evidence Report (form CMS-2728). Follow-up extended to December 31, 2006. Cause of death was ascertained from the Death Notification (form CMS-2746). Results: Crude firstyear cancer-specific mortality rates, per 1,000 patient-years, 1995-2005, were as follows: 13.8, 13.7, 14.2, 14.9, 13.8, 15.4, $15.4,16.5,16.4,15.8,15.2$. Mortality rates remained stable year to year within subsequent follow-up intervals; for the first and last annual cohorts, mortality rates by follow-up in-
\end{abstract}

terval were: year 2, 9.1 and 8.7; year 3, 8.6 and 8.3; years 4-5, 7.9 and 6.8. Annual comparisons were similar after adjustment for patient characteristics at dialysis initiation. Conclusion: Cancer-specific mortality rates remained stable among US hemodialysis patients between 1995 and 2005.

Copyright $\odot 2010$ S. Karger AG, Basel

\section{Introduction}

Management of anemia in hemodialysis patients with cancer has become challenging, not least because recommended usage of erythropoiesis-stimulating agent (ESA) therapy differs considerably depending on the specific condition [1]. The concern that ESA therapy may decrease survival in patients with cancer [2-4] may apply to a sizeable subset of the hemodialysis population, as many latter-day patients begin dialysis treatment with a previous diagnosis of cancer within the 10 years preceding end-stage renal disease (ESRD) development. For hemodialysis patients receiving ESAs in the USA, the recommendation is to individualize dosing to achieve and

This study was accepted for oral presentation at the 2009 American Society of Nephrology Meeting.

\section{KARGER}

Fax +41 613061234 E-Mail karger@karger.ch www.karger.com
(ㄷ) 2010 S. Karger AG, Basel

0250-8095/10/0316-0518\$26.00/0

Accessible online at:

www.karger.com/ajn
Robert N. Foley, MB

Chronic Disease Research Group

Minneapolis Medical Research Foundation

914 South 8th Street, Suite S-406, Minneapolis, MN 55404 (USA)

Tel. +1 612347 5979, Fax +1 612347 5980, E-Mail RFoley@ cdrg.org 
maintain hemoglobin levels within the range of 10-12 g/dl.' For cancer patients, ESA treatment involves using 'the lowest dose needed to avoid red blood cell transfusion'; in addition, ESAs are indicated only for 'treatment of anemia due to concomitant myelosuppressive chemotherapy' [1]. These differences in dosing and indications between the cancer and ESRD populations make treatment recommendations confusing to patients and providers.

US hemodialysis patient ESA doses have escalated; epoetin doses rose from approximately 6,000 to nearly 20,000 units per week between 1991 and 2007 [5]. If high ESA doses truly increase cancer risk in hemodialysis patients, it seems reasonable to expect that cancer-specific mortality rates of hemodialysis patients should be rising. To date, no large clinical trials have assessed effects of ESA dose in the important subgroup of hemodialysis patients with prior or ongoing cancer. In the absence of such trials, and considering that ESA doses have tripled since the early 1990s, we set out to perform a national, nonexperimental, observational surveillance study comparing temporal trends in cancer-specific mortality among US hemodialysis patients.

\section{Methods}

Objectives

Among incident patients beginning maintenance hemodialysis therapy between May 1, 1995, and December 31, 2005, our objectives were to enumerate the following: (1) yearly trends in unadjusted and comorbidity-adjusted cancer-specific mortality rates, the primary objectives; (2) yearly trends in cardiovascular mortality rates, and (3) yearly trends in all-cause mortality.

\section{Study Design and Population}

We used a retrospective, incident cohort study design, with time zero set at initiation of dialysis therapy. The study cohort included incident hemodialysis patients with a first service date for renal replacement therapy between May 1, 1995, and December 31, 2005. The former date was chosen because a revised version of the Centers for Medicare \& Medicaid Services (CMS) Medical Evidence Report (form CMS-2727) was introduced in April 1995; the revised form assessed comorbidity, biochemical data, and height and weight at hemodialysis initiation. The latter date was chosen to allow the opportunity for at least 1 year of potential follow-up for all patients. Included patients were residents of the 50 US states, the District of Columbia, Puerto Rico, or the US territories, with complete demographic data and with a Medical Evidence Report filed at dialysis initiation. For the main analysis, all adult patients aged $\geq 20$ years were included, irrespective of Medicare status. In supplemental analysis of patients aged $\geq 67$ years at dialysis initiation, both the Medical Evidence Report and Medicare claims were used to assess comorbidity. These patients were required to have Medicare as primary payer with Part A and
Part B coverage for 2 years before dialysis initiation to allow for more complete assessment of comorbidity, disease severity, and cancer history.

\section{Analysis}

Mortality rates for all incident hemodialysis patients aged $\geq 20$ years, and for the subgroup with previous cancer, are presented here, with comorbidity defined by the Medical Evidence Report filed at dialysis initiation [6, 7]. As findings from several supplemental sensitivity analyses were similar, they are not reported here. These supplemental analyses were restricted to the cohort aged $\geq 67$ years at dialysis initiation, and were performed for the following groups: all patients with comorbidity defined by the Medical Evidence Report; the subgroup with prior malignancy, with prior malignancy and other comorbid conditions defined by the Medical Evidence Report; all patients with comorbidity defined by Medicare claims, and the subgroup with prior malignancy, with prior malignancy and other comorbid conditions defined by Medicare claims. Additional analyses were performed separately within each stratum of the following variables: diabetes status, race, urban or rural residence, provider type, ESA use before hemodialysis initiation, and, for the population aged $\geq 67$ years, nephrologist care before hemodialysis initiation.

Dates and causes of death were ascertained from the Death Notification (form CMS-2726) [8]. Patients were followed from the first service date for renal replacement therapy and censored at the earliest date of transplant, recovery of renal function, December 31, 2006, or 5 years of follow-up. Unadjusted mortality rates were computed from survival estimates using the KaplanMeier method. Standard errors of the unadjusted rates per 1,000 patient-years (shown in tables A1 and A2 in the Appendix) were estimated using the delta method. Rates were also adjusted for age, sex, race, ethnicity, primary cause of renal disease, and comorbid conditions. Information on the following comorbid conditions was obtained from the Medical Evidence Report: atherosclerotic heart disease, congestive heart failure, stroke/transient ischemic attack, peripheral vascular disease, chronic obstructive pulmonary disease, and cancer. Rates restricted to cancer patients were adjusted for all of the listed conditions except cancer.

To assess trends in ESA dosing among cancer patients, epoetin alfa doses and hemoglobin values were described among epoetin-treated incident hemodialysis patients aged $\geq 20$ years with Medicare coverage and with a prior cancer diagnosis reported on the Medical Evidence Report at dialysis initiation. Mean hemoglobin and mean epoetin dose per outpatient week were computed by calendar year and month during the first 5 years following dialysis initiation. Epoetin dose was computed per outpatient week because epoetin claims are unavailable during hospitalizations.

Supplemental analyses were performed using alternative analytical methods. Mortality rates were adjusted for ESA dose during the first calendar month after initiation in the population aged $\geq 67$ years who survived and were uncensored at the end of the month. Also, cause of death was missing for $12 \%$ of reported death events (873,493 patients; 546,757 death events; among these, 67,349 missing cause of death). In the main analyses, deaths with missing cause were counted as events in the all-cause death rates and these patients were censored in the cause-specific death rates. To assess the impact of these missing data on the primary 
Table 1. Patient characteristics (as column percentages) at hemodialysis initiation, ages $\geq 20$ years

\begin{tabular}{|c|c|c|c|c|c|c|c|c|c|c|c|}
\hline $\begin{array}{r}\text { Year: } \\
\text { Number of patients: }\end{array}$ & $\begin{array}{l}1995 \\
37,970\end{array}$ & $\begin{array}{l}1996 \\
64,250\end{array}$ & $\begin{array}{l}1997 \\
70,583\end{array}$ & $\begin{array}{l}1998 \\
76,438\end{array}$ & $\begin{array}{l}1999 \\
80,554\end{array}$ & $\begin{array}{l}2000 \\
84,035\end{array}$ & $\begin{array}{l}2001 \\
87,243\end{array}$ & $\begin{array}{l}2002 \\
89,677\end{array}$ & $\begin{array}{l}2003 \\
92,132\end{array}$ & $\begin{array}{l}2004 \\
94,244\end{array}$ & $\begin{array}{l}2005 \\
96,367\end{array}$ \\
\hline \multicolumn{12}{|l|}{ Age, years } \\
\hline $20-44$ & 16.1 & 15.4 & 14.3 & 14.0 & 13.4 & 13.1 & 12.6 & 12.4 & 12.1 & 11.9 & 12.1 \\
\hline $45-64$ & 34.5 & 34.1 & 33.9 & 34.5 & 34.7 & 34.8 & 34.9 & 35.0 & 35.8 & 36.3 & 36.5 \\
\hline $65-74$ & 28.2 & 28.6 & 28.3 & 27.3 & 26.5 & 26.3 & 26.4 & 25.4 & 24.7 & 24.5 & 23.8 \\
\hline$\geq 75$ & 21.2 & 22.0 & 23.4 & 24.2 & 25.3 & 25.9 & 26.1 & 27.3 & 27.4 & 27.3 & 27.5 \\
\hline \multicolumn{12}{|l|}{ Sex } \\
\hline Men & 52.3 & 53.2 & 53.3 & 53.1 & 53.5 & 53.4 & 53.8 & 54.4 & 54.2 & 55.2 & 55.6 \\
\hline Women & 47.7 & 46.8 & 46.7 & 46.9 & 46.5 & 46.6 & 46.2 & 45.6 & 45.8 & 44.8 & 44.4 \\
\hline \multicolumn{12}{|l|}{ Race } \\
\hline White & 62.0 & 62.5 & 63.3 & 63.1 & 63.7 & 64.3 & 64.4 & 64.1 & 63.9 & 64.5 & 64.8 \\
\hline African-American & 32.1 & 31.4 & 30.9 & 30.9 & 30.1 & 29.5 & 29.5 & 29.8 & 29.7 & 29.0 & 29.4 \\
\hline Other & 5.9 & 6.1 & 5.8 & 6.0 & 6.2 & 6.2 & 6.1 & 6.2 & 6.4 & 6.5 & 5.8 \\
\hline \multicolumn{12}{|l|}{ Ethnicity } \\
\hline Hispanic & 12.2 & 11.8 & 11.4 & 11.4 & 11.9 & 13.4 & 12.3 & 12.6 & 13.1 & 13.3 & 13.2 \\
\hline Non-Hispanic & 87.8 & 88.2 & 88.6 & 88.6 & 88.1 & 86.6 & 87.7 & 87.4 & 86.9 & 86.7 & 86.8 \\
\hline \multicolumn{12}{|l|}{ Primary cause of renal disease } \\
\hline Diabetes & 42.8 & 43.7 & 44.5 & 44.9 & 45.1 & 46.0 & 46.3 & 45.5 & 45.7 & 45.9 & 45.6 \\
\hline Hypertension & 27.5 & 27.9 & 28.1 & 27.8 & 28.0 & 27.7 & 28.0 & 28.3 & 28.9 & 28.4 & 28.1 \\
\hline Glomerulonephritis & 10.8 & 10.3 & 9.7 & 9.3 & 9.0 & 8.3 & 8.0 & 7.9 & 7.4 & 7.3 & 6.8 \\
\hline Other & 18.9 & 18.1 & 17.6 & 18.0 & 17.9 & 18.1 & 17.8 & 18.2 & 18.0 & 18.4 & 19.4 \\
\hline Congestive heart failure & 32.5 & 33.6 & 34.5 & 34.1 & 33.1 & 33.8 & 33.4 & 32.6 & 33.3 & 33.8 & 35.2 \\
\hline Stroke/transient ischemic attack & 8.5 & 9.0 & 9.5 & 9.5 & 9.5 & 9.6 & 9.9 & 9.7 & 9.7 & 9.5 & 10.1 \\
\hline Peripheral vascular disease & 14.5 & 14.6 & 15.3 & 15.3 & 14.9 & 15.0 & 14.9 & 14.5 & 14.7 & 14.6 & 15.2 \\
\hline Chronic obstructive pulmonary disease & 7.2 & 7.2 & 7.5 & 7.4 & 7.5 & 7.8 & 7.9 & 8.0 & 8.4 & 8.6 & 9.3 \\
\hline Cancer & 5.2 & 5.0 & 5.2 & 5.4 & 5.6 & 5.9 & 6.2 & 6.5 & 6.5 & 6.5 & 7.4 \\
\hline Atherosclerotic heart disease & 25.1 & 25.8 & 26.9 & 27.2 & 27.3 & 28.1 & 28.6 & 28.2 & 28.3 & 28.4 & 24.9 \\
\hline
\end{tabular}

objective, supplemental analyses imputed cause of death for the missing values and produced cancer-specific death rates for the population aged $\geq 20$ years. Resulting mortality trends from these supplemental analyses were similar and are not reported here.

Further supplemental analyses compared adjusted mortality rates by pre-ESRD ESA use and by the following factors, assessed during the first calendar month after initiation: mean hemoglobin, mean epoetin dose per outpatient week, and ESA type. Cohorts and methods generally followed those for the main analyses with a few differences. Rates by pre-ESRD ESA use included incident Medicare and non-Medicare hemodialysis patients aged $\geq 20$ years and excluded patients without indication of pre-ESRD ESA use on the Medical Evidence Report. To allow availability of complete claims, rates by mean hemoglobin, mean epoetin dose per outpatient week, and ESA type were computed among incident Medicare hemodialysis patients aged $\geq 67$ years, and patients were excluded who were hospitalized during the complete calendar month following initiation. Included patients were alive and uncensored at the end of the first calendar month following the month of initiation, and follow-up began at the end of this month. Additional inclusion criteria were applied to provide complete data: for rates by mean hemoglobin, included patients were epoetin-treated and had at least one valid hemoglobin value during the first calendar month after initiation; for rates by mean epoetin dose, included patients were both with and without epoetin and had a valid hemoglobin or hematocrit value on the Medical Evidence Report at initiation, and epoetin-treated patients had valid dose data during the first calendar month after initiation, and for rates by ESA type, included patients were treated with epoetin or darbepoetin during the first calendar month after initiation, but not with both. Rates by groups among patients aged $\geq 67$ years were reported for all-cause mortality due to instability of model-based estimates for cause-specific events. Rates were adjusted for age, sex, race, ethnicity, primary cause of renal disease, and comorbid conditions from the Medical Evidence Report, and rates by epoetin dose were also adjusted for baseline hemoglobin from the Medical Evidence Report. Since darbepoetin claims became available during 2004, rates by ESA type were restricted to first-year mortality among 2005 incident patients.

Adjusted mortality rates were calculated using a model-based adjustment method and Cox proportional hazards models. Adjusted rates reflect the distribution of a reference cohort, in this case, patients who initiated hemodialysis in 1997. With this method, the survival and parameter estimates from the model were used to calculate an estimated mortality rate for each patient in the reference cohort. Adjusted rates were then computed as the 
Fig. 1. All-cause, cardiovascular and cancer-specific death rates (y-axis, per 1,000 patient-years) by year of hemodialysis initiation ( $\mathrm{x}$-axis), ages $\geq 20$ years, unadjusted and adjusted for all baseline characteristics shown in table 1 . All = All-cause mortality; $\mathrm{Ca}=$ cancer mortality; $\mathrm{CV}=$ cardiovascular mortality.

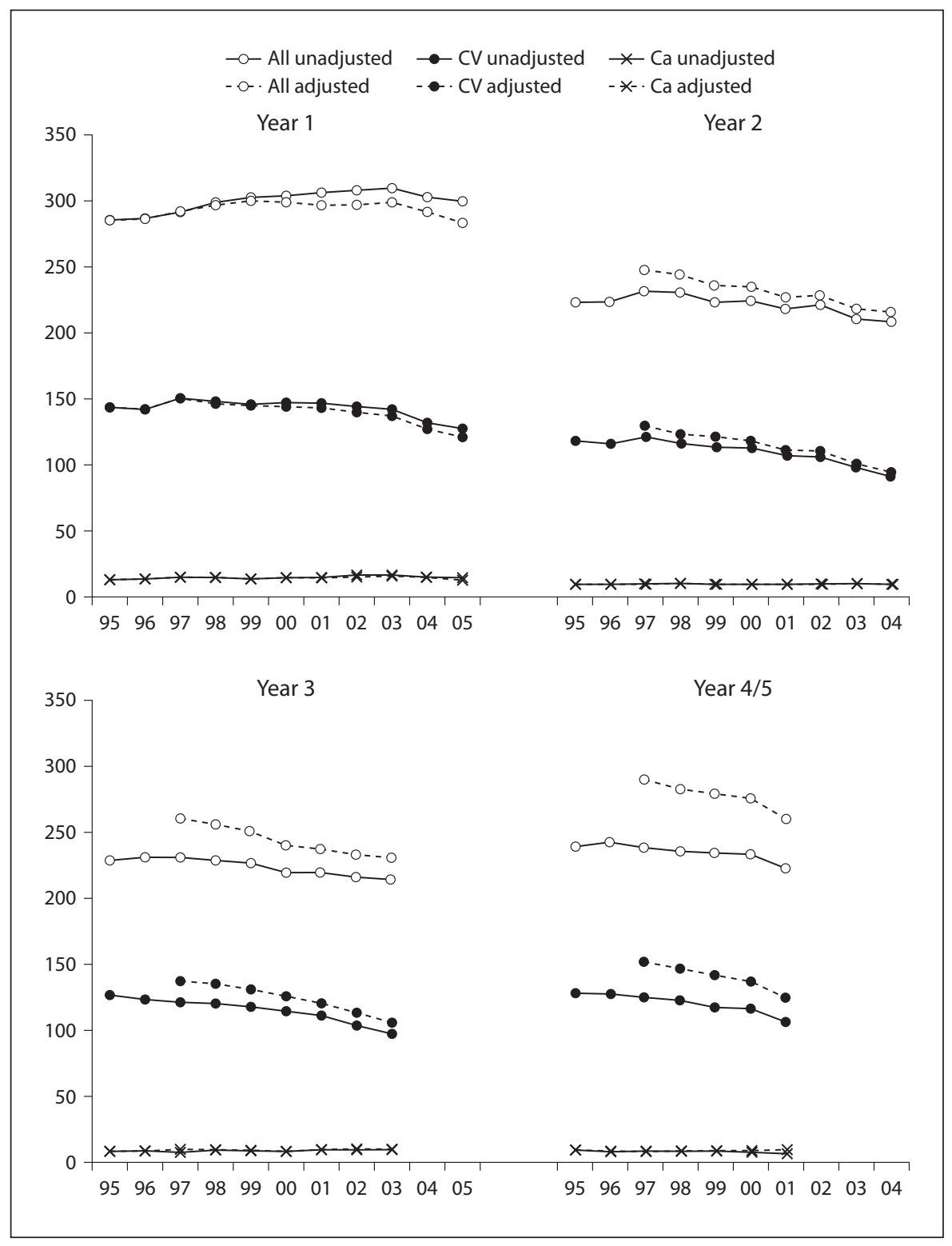

weighted average of these individual rates, using the time at risk for each patient in the reference cohort as weight. To accommodate the proportional hazards assumption, parameter estimates were allowed to vary for each follow-up year. Follow-up years 4 and 5 were pooled to increase stability of rates later during followup as the number of censored patients increased. Standard errors of adjusted rates were calculated using the computationally intensive bootstrap method. To stabilize adjusted rates, model-based estimates were computed using the current and previous 2 years of data weighted by 1 , one-fourth, and one-eighth, respectively. Therefore, as the previous 2 years of data were also used to compute each year's rate, adjusted rates were reported from 1997, not 1995, on. SAS Version 9.1 (SAS Institute, Inc., Cary, N.C., USA) was used for data assembly.

Cancer Mortality in Dialysis

\section{Results}

Table 1 shows the characteristics of all included patients, aged $\geq 20$ years, at dialysis initiation 1995 through 2005 ; over time, the proportion of patients aged $\geq 75$ years increased from $21.2 \%$ in 1995 to $27.5 \%$ in 2005 , and the proportion with prior cancer reported on the Medical Evidence Report increased from 5.2 to $7.4 \%$.

Figure 1 shows all-cause, cardiovascular, and cancerspecific death rates. In the first year of dialysis therapy, overall death rates have declined since 2003 in both adjusted and unadjusted analytical models, and death from 
Table 2. Patient characteristics (as column percentages) at hemodialysis initiation, ages $\geq 20$ years, prior cancer diagnosis on medical evidence report

\begin{tabular}{|c|c|c|c|c|c|c|c|c|c|c|c|}
\hline $\begin{array}{r}\text { Year: } \\
\text { Number of patients: }\end{array}$ & $\begin{array}{l}1995 \\
1,979\end{array}$ & $\begin{array}{l}1996 \\
3,239\end{array}$ & $\begin{array}{l}1997 \\
3,690\end{array}$ & $\begin{array}{l}1998 \\
4,147\end{array}$ & $\begin{array}{l}1999 \\
4,494\end{array}$ & $\begin{array}{l}2000 \\
4,956\end{array}$ & $\begin{array}{l}2001 \\
5,371\end{array}$ & $\begin{array}{l}2002 \\
5,845\end{array}$ & $\begin{array}{l}2003 \\
5,947\end{array}$ & $\begin{array}{l}2004 \\
6,163\end{array}$ & $\begin{array}{l}2005 \\
7,153\end{array}$ \\
\hline \multicolumn{12}{|l|}{ Age, years } \\
\hline $20-44$ & 4.7 & 4.0 & 3.5 & 3.4 & 3.4 & 3.0 & 2.9 & 2.9 & 2.7 & 2.6 & 2.6 \\
\hline $45-64$ & 25.0 & 25.0 & 23.0 & 25.4 & 24.9 & 23.8 & 23.8 & 23.9 & 24.1 & 24.3 & 24.6 \\
\hline $65-74$ & 34.2 & 35.7 & 36.2 & 34.0 & 33.1 & 32.4 & 33.0 & 30.9 & 30.8 & 30.3 & 29.0 \\
\hline$\geq 75$ & 36.1 & 35.3 & 37.3 & 37.3 & 38.6 & 40.8 & 40.4 & 42.3 & 42.4 & 42.8 & 43.8 \\
\hline \multicolumn{12}{|l|}{ Sex } \\
\hline Men & 58.6 & 62.6 & 62.1 & 62.1 & 60.1 & 61.0 & 60.6 & 60.7 & 60.9 & 60.3 & 62.3 \\
\hline Women & 41.4 & 37.4 & 37.9 & 37.9 & 39.9 & 39.0 & 39.4 & 39.3 & 39.1 & 39.7 & 37.7 \\
\hline \multicolumn{12}{|l|}{ Race } \\
\hline White & 74.5 & 75.5 & 75.9 & 76.1 & 76.2 & 75.8 & 76.2 & 76.6 & 76.8 & 76.5 & 77.0 \\
\hline African-American & 22.2 & 21.2 & 21.2 & 21.1 & 20.7 & 20.6 & 21.1 & 20.1 & 20.4 & 20.4 & 20.3 \\
\hline Other & 3.3 & 3.3 & 2.9 & 2.8 & 3.1 & 3.6 & 2.7 & 3.3 & 2.8 & 3.1 & 2.8 \\
\hline \multicolumn{12}{|l|}{ Ethnicity } \\
\hline Hispanic & 6.1 & 6.0 & 6.0 & 5.6 & 5.5 & 7.4 & 5.5 & 5.7 & 6.0 & 5.9 & 6.0 \\
\hline Non-Hispanic & 93.9 & 94.0 & 94.0 & 94.4 & 94.5 & 92.6 & 94.5 & 94.3 & 94.0 & 94.1 & 94.0 \\
\hline \multicolumn{12}{|l|}{ Primary cause of renal disease } \\
\hline Diabetes & 23.6 & 23.8 & 26.6 & 26.4 & 25.6 & 25.6 & 26.9 & 26.3 & 26.1 & 26.4 & 27.7 \\
\hline Hypertension & 23.5 & 24.4 & 25.4 & 23.9 & 24.6 & 25.1 & 26.8 & 25.0 & 26.9 & 25.7 & 25.6 \\
\hline Glomerulonephritis & 10.3 & 8.5 & 8.2 & 8.7 & 8.1 & 7.6 & 7.0 & 6.8 & 6.4 & 6.3 & 5.7 \\
\hline Other & 42.6 & 43.3 & 39.7 & 41.0 & 41.7 & 41.6 & 39.3 & 41.8 & 40.6 & 41.7 & 41.0 \\
\hline Congestive heart failure & 30.5 & 32.3 & 35.3 & 32.5 & 32.4 & 31.6 & 31.9 & 30.7 & 31.2 & 32.4 & 32.6 \\
\hline Stroke/transient ischemic attack & 8.9 & 11.1 & 10.5 & 10.2 & 10.9 & 11.4 & 11.8 & 11.2 & 10.8 & 11.1 & 11.8 \\
\hline Peripheral vascular disease & 13.4 & 15.0 & 15.2 & 15.0 & 13.3 & 14.1 & 15.7 & 14.0 & 14.4 & 14.0 & 14.6 \\
\hline Cancer & 100.0 & 100.0 & 100.0 & 100.0 & 100.0 & 100.0 & 100.0 & 100.0 & 100.0 & 100.0 & 100.0 \\
\hline Chronic obstructive pulmonary disease & 10.2 & 11.6 & 13.0 & 11.5 & 11.5 & 12.4 & 13.1 & 11.9 & 12.9 & 13.4 & 13.9 \\
\hline Atherosclerotic heart disease & 27.4 & 29.5 & 31.4 & 30.6 & 30.2 & 32.4 & 32.8 & 32.3 & 32.5 & 33.4 & 28.5 \\
\hline
\end{tabular}

cardiovascular disease has declined steadily since 1997; trends for years 2, 3, and 4/5 were broadly similar, except for declines in all-cause mortality since 1997. Regarding the main study outcome, cancer-specific mortality rates remained stable in each interval of follow-up, whether or not adjustment was made for baseline covariate patterns.

Table 2 shows the characteristics of patients with prior cancer reported on the Medical Evidence Report in 1995 through 2005; over time, the proportion of patients aged $\geq 75$ years increased from $36.1 \%$ in 1995 to $43.8 \%$ in 2005 , and the proportion of men increased from 58.6 to $62.3 \%$. Death rate trends in this subgroup of patients with cancer paralleled rate trends in the overall population (fig. 2).

Supplemental analyses produced the following adjusted first-year mortality rates per 1,000 patient-years among incident hemodialysis patients aged $\geq 20$ years from 1997 to 2005 by pre-ESRD ESA use: with ESA, allcause mortality, 238, 243, 244, 244, 245, 252, 243, 244, 230; without ESA, all-cause mortality, 309, 317, 320, 320, $322,320,327,317,305$; with ESA, cancer mortality, 12.5,
$14.2,11.5,13.4,13.7,14.8,15.3,12.9,11.9$; without ESA, cancer mortality, 14.7, 14.7, 14.0, 15.1, 14.9, 15.0, 15.3, 15.5, 13.4; with ESA, cardiovascular mortality, 123, 122, 118, $118,116,122,113,110,100$; without ESA, cardiovascular mortality, 159, 157, 155, 155, 156, 149, 149, 137, 130.

The following include adjusted first-year all-cause mortality rates per 1,000 patient-years from 1997 to 2005 among incident hemodialysis patients aged $\geq 67$ years by mean hemoglobin and mean epoetin dose per outpatient week during the month after initiation: hemoglobin $<9 \mathrm{~g} /$ $\mathrm{dl}, 498,524,522,547,589,570,612,635,640 ; 9$ to $<10 \mathrm{~g} / \mathrm{dl}$, $454,453,459,491,503,498,541,511,510 ; 10$ to $<11 \mathrm{~g} / \mathrm{dl}$, $392,399,432,442,439,445,453,453,436 ; 11$ to $<12 \mathrm{~g} / \mathrm{dl}$, 388 , 393, 391, 384, 374, 380, 401, 400, 378; $\geq 12$ g/dl, 381, 370, 364, 360, 340, 334, 323, 328, 329; without epoetin, 513, $596,559,501,557,611,621,604,508$; $<17,000$ units per week, 410, 430, 422, 420, 423, 418, 412, 422, 398; $\geq 17,000$ units per week, 437, 410, 430, 439, 428, 426, 431, 425, 415. In 2005, adjusted first-year all-cause mortality rates per 1,000 patient years were 404 and 345, respectively, for pa- 
Fig. 2. All-cause, cardiovascular and cancer-specific death rates (y-axis, per 1,000 patient years) by year of hemodialysis initiation ( $\mathrm{x}$-axis), ages $\geq 20$ years with prior cancer diagnosis on Medical Evidence Form, unadjusted and adjusted for all baseline characteristics shown in table 2 except cancer. All = All-cause mortality; $\mathrm{Ca}=$ cancer mortality; $\mathrm{CV}=$ cardiovascular mortality.

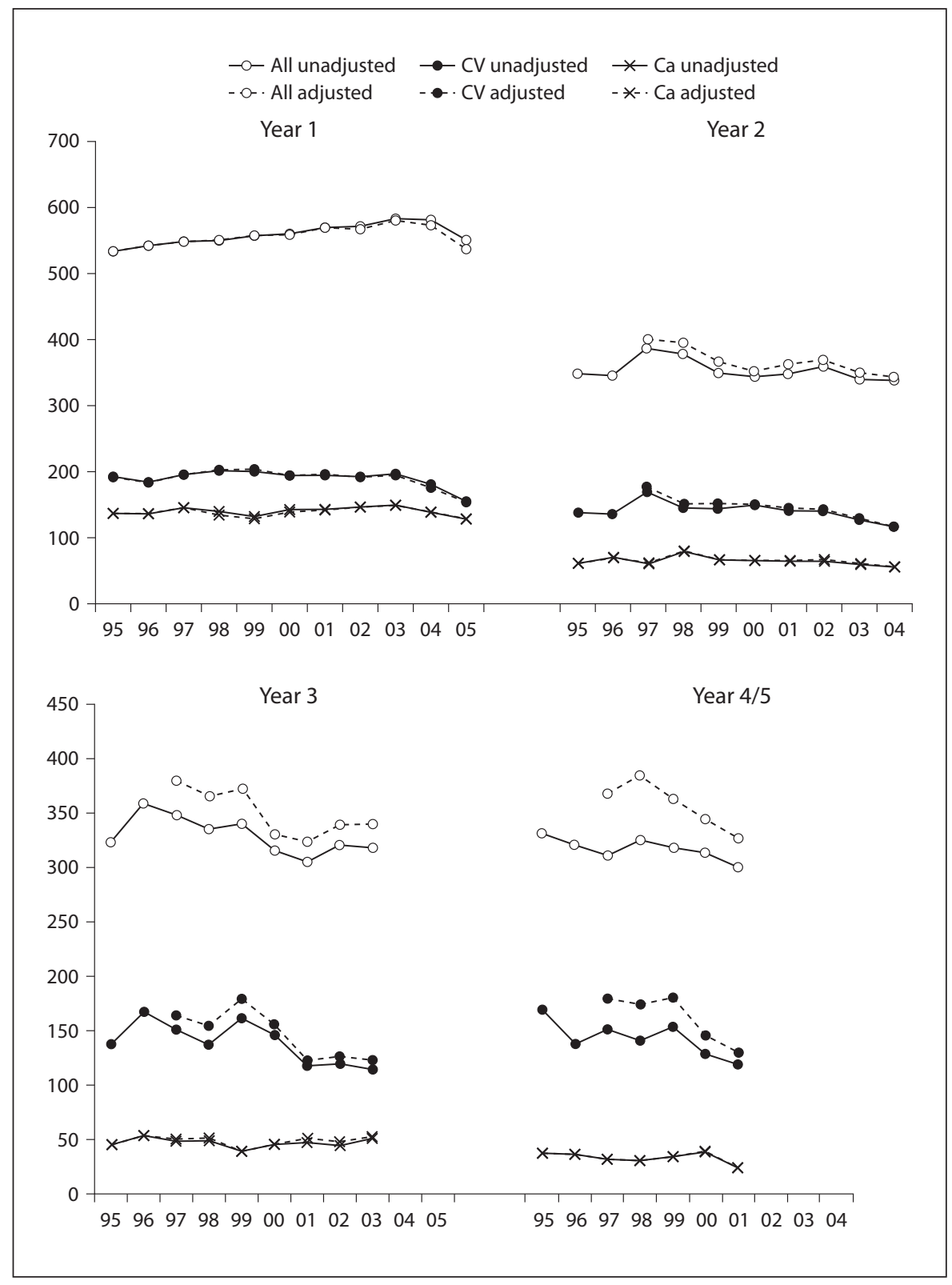

tients treated with epoetin and darbepoetin. Groups without pre-ESRD ESA use, with lower hemoglobin, and without epoetin use in the first month after initiation were associated with higher adjusted first-year all-cause mortality rates, while rates were generally similar between dose groups. Mortality rates in 2005 were slightly lower among darbepoetin-treated than epoetin-treated patients. Among patients with a prior cancer diagnosis, epoetin dose rose from approximately 10,700 units per week in June 1995 to 19,500 units per week in December 2006, and during the same time hemoglobin rose from 10.1 to $12.0 \mathrm{~g} / \mathrm{dl}$ (fig. 3).

\section{Discussion}

Anemia management has become an important dayto-day clinical management issue in oncology patients. Many ESA trials have been performed, and several informative meta-analyses have been published examining hard clinical outcomes, including death [9-18]. The largest of these meta-analyses, both including more than 13,000 patients from several trials, showed that ESAs increased mortality by approximately $10-17 \%$, an effect largely related to thromboembolic events, especially ve- 


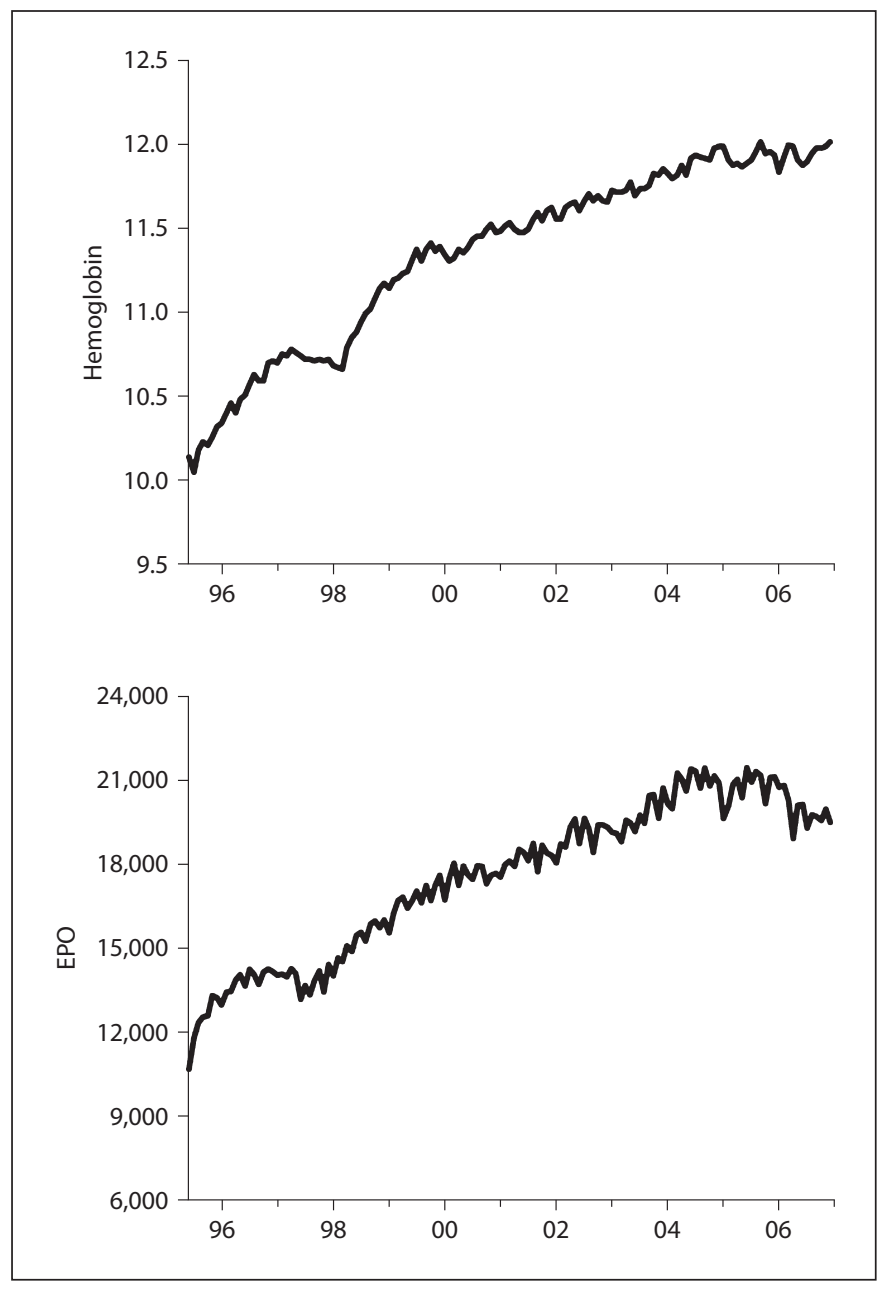

Fig. 3. Mean monthly hemoglobin (y-axis, g/dl) and mean epoetin alfa (EPO) dose per outpatient week (y-axis, units) by calendar year and month (x-axis) during the first 5 years after hemodialysis initiation, ages $\geq 20$ years with prior cancer diagnosis on Medical Evidence Report and with Medicare coverage.

nous thromboembolic events. While these meta-analyses have not demonstrated, in aggregate, that ESA therapy leads to more rapid tumor progression, the mode of action of currently prescribed ESAs suggests that this remains an open question. For example, erythropoietin receptors are found on a large variety of non-erythroid cell types, and, ultimately, inhibition of apoptosis appears to be a major function of erythropoietin [19-22].

In the USA, approximately $7.7 \%$ of patients initiate maintenance hemodialysis with a prior diagnosis of cancer [23]. For several years, cancer rates have been known to be greater than expected in patients on maintenance dialysis therapy. For example, one well-known study re- ported cancer rates in 831,804 patients starting dialysis between 1980 and 1994 in the USA, Europe, Australia, and New Zealand; standardized incidence ratios for cancers of the kidney and bladder were 3.6 and 1.5, respectively [24].

If ESAs truly predispose to malignancy in hemodialysis populations, and lead to death exclusively through cancer, cancer-specific mortality rates should be observed to rise in parallel with rising ESA doses, and other non-cancerspecific mortality rates might be expected to remain static or to decline. Conversely, if ESAs lead to death exclusively through cardiovascular disease, cardiovascular mortality should be observed to rise in parallel with rising ESA use. In this study, we found that yearly cancer mortality rates were static throughout an observation period of 10 years, even though ESA doses are known to have escalated dramatically during that time. In addition, we observed modest declines in overall and cardiovascular mortality. These observational findings were insensitive to covariate adjustment and several different analytical approaches.

As this was an observational, non-experimental study, it is a limited vehicle for assessing cause and effect. Associations between mortality and epoetin use and dose from supplemental analyses are limited by confounding by indication, a common issue with observational studies. ESA administration and dosing are undoubtedly influenced by disease burden and associated with other unmeasured aspects of care, and adjustments are unlikely to completely control for these differences. Other limitations include retrospective design and dependence on administrative data to define baseline characteristics. Assigning cause of death is a difficult issue, especially in populations with large burdens of comorbid illness. Although little information is available to gauge the accuracy of death classification among dialysis patients, the Hemodialysis (HEMO) Study, funded by the National Institutes of Health, has been an informative exception. In the HEMO Study, cause of death was determined by a committee of trained physicians. Using the HEMO Study classification system as gold standard, on the Death Notification (form CMS-2746, used in this study), misclassification of cause of death was most pronounced for cardiovascular disease. Sensitivity for the Death Notification form ranged from 9.1\% for congestive heart failure to $91.7 \%$ for malignancy; specificity was high for all conditions and a kappa statistic of 0.95 was observed for malignancy [25]. Finally, as this study used mortality as its main outcome, we cannot exclude the possibility that non-fatal malignancy rates may have increased throughout the observation period.

Despite its limitations, we believe that this study provides clinically relevant information, particularly to pro- 
viders confronted with the issue of how to manage anemia in patients with both cancer and ESRD. While large trials, with oncologically relevant outcomes, are needed in this patient population, the logistical barriers to completing such trials are likely to be formidable. While these trials are awaited, targeted epidemiological studies may be helpful and can guide clinical practice until safety data are developed for the dialysis population that also carries a diagnosis of cancer.

\section{Acknowledgments}

This study was supported by a research contract from Amgen Inc., Thousand Oaks, Calif. The authors wish to thank Chronic Disease Research Group colleagues Shane Nygaard, BA, for manuscript preparation, and Nan Booth, MSW, MPH, for manuscript editing.

\section{Appendix}

Table A1. Standard errors of unadjusted all-cause, cardiovascular, and cancer mortality rates (per 1,000 patient-years) in figure 1, ages $\geq 20$ years

\begin{tabular}{|c|c|c|c|c|c|c|c|c|c|c|c|c|}
\hline \multirow[b]{3}{*}{ Incident year: } & \multicolumn{12}{|c|}{ Mortality, years } \\
\hline & \multicolumn{4}{|c|}{ all-cause } & \multicolumn{4}{|c|}{ cancer } & \multicolumn{4}{|c|}{ cardiovascular } \\
\hline & 1 & 2 & 3 & $4 / 5$ & 1 & 2 & 3 & $4 / 5$ & 1 & 2 & 3 & $4 / 5$ \\
\hline 1995 & 3.0 & 3.1 & 3.6 & 3.2 & 0.7 & 0.6 & 0.7 & 0.6 & 2.1 & 2.2 & 2.7 & 2.3 \\
\hline 1996 & 2.3 & 2.4 & 2.8 & 2.5 & 0.5 & 0.5 & 0.5 & 0.4 & 1.6 & 1.7 & 2.0 & 1.8 \\
\hline 1997 & 2.2 & 2.3 & 2.7 & 2.4 & 0.5 & 0.5 & 0.5 & 0.4 & 1.6 & 1.7 & 1.9 & 1.7 \\
\hline 1998 & 2.2 & 2.2 & 2.5 & 2.2 & 0.5 & 0.4 & 0.5 & 0.4 & 1.5 & 1.6 & 1.8 & 1.6 \\
\hline 1999 & 2.1 & 2.1 & 2.5 & 2.2 & 0.5 & 0.4 & 0.5 & 0.4 & 1.5 & 1.5 & 1.8 & 1.5 \\
\hline 2000 & 2.1 & 2.1 & 2.4 & 2.1 & 0.5 & 0.4 & 0.4 & 0.4 & 1.5 & 1.5 & 1.7 & 1.5 \\
\hline 2001 & 2.1 & 2.0 & 2.3 & 2.0 & 0.5 & 0.4 & 0.5 & 0.3 & 1.4 & 1.4 & 1.6 & 1.4 \\
\hline 2002 & 2.0 & 2.0 & 2.3 & & 0.5 & 0.4 & 0.4 & & 1.4 & 1.4 & 1.6 & \\
\hline 2003 & 2.0 & 1.9 & 2.2 & & 0.5 & 0.4 & 0.4 & & 1.4 & 1.3 & 1.5 & \\
\hline 2004 & 2.0 & 1.9 & & & 0.5 & 0.4 & & & 1.3 & 1.3 & & \\
\hline 2005 & 1.9 & & & & 0.4 & & & & 1.3 & & & \\
\hline
\end{tabular}

Table A2. Standard errors of unadjusted all-cause, cardiovascular, and cancer mortality rates (per 1,000 patient-years) in figure 2, ages $\geq 20$ years, prior cancer diagnosis on medical evidence report

\begin{tabular}{|c|c|c|c|c|c|c|c|c|c|c|c|c|}
\hline \multirow[b]{3}{*}{ Incident year: } & \multicolumn{12}{|c|}{ Mortality, years } \\
\hline & \multicolumn{4}{|c|}{ all-cause } & \multicolumn{4}{|c|}{ cancer } & \multicolumn{4}{|c|}{ cardiovascular } \\
\hline & 1 & 2 & 3 & $4 / 5$ & 1 & 2 & 3 & $4 / 5$ & 1 & 2 & 3 & $4 / 5$ \\
\hline 1995 & 19.1 & 19.3 & 22.2 & 20.7 & 9.7 & 8.0 & 8.3 & 7.1 & 11.5 & 12.2 & 14.5 & 14.9 \\
\hline 1996 & 15.1 & 15.1 & 18.6 & 16.4 & 7.5 & 6.8 & 7.2 & 5.5 & 8.8 & 9.4 & 12.7 & 10.8 \\
\hline 1997 & 14.3 & 15.2 & 17.5 & 15.1 & 7.3 & 5.9 & 6.5 & 4.9 & 8.5 & 10.1 & 11.5 & 10.5 \\
\hline 1998 & 13.5 & 14.2 & 16.1 & 14.6 & 6.8 & 6.3 & 6.1 & 4.4 & 8.1 & 8.8 & 10.2 & 9.7 \\
\hline 1999 & 13.1 & 13.1 & 15.5 & 13.9 & 6.4 & 5.7 & 5.2 & 4.5 & 7.8 & 8.4 & 10.7 & 9.7 \\
\hline 2000 & 12.5 & 12.4 & 14.2 & 12.9 & 6.3 & 5.3 & 5.4 & 4.4 & 7.4 & 8.2 & 9.7 & 8.3 \\
\hline 2001 & 12.2 & 12.1 & 13.4 & 12.0 & 6.0 & 5.1 & 5.3 & 3.3 & 7.2 & 7.6 & 8.3 & 7.6 \\
\hline 2002 & 11.7 & 11.8 & 13.4 & & 6.0 & 5.0 & 4.9 & & 6.8 & 7.4 & 8.2 & \\
\hline 2003 & 11.8 & 11.5 & 13.2 & & 5.9 & 4.7 & 5.2 & & 6.9 & 6.9 & 7.9 & \\
\hline 2004 & 11.6 & 11.2 & & & 5.6 & 4.5 & & & 6.5 & 6.6 & & \\
\hline 2005 & 10.4 & & & & 5.0 & & & & 5.5 & & & \\
\hline
\end{tabular}




\section{References}

1 Food and Drug Association. Epogen ${ }^{\circledR}$ (epoetin- $\alpha$ ) for injection. November 19, 2008. Available at http://www.accessdata.fda. gov/drugsatfda_docs/label/2008/ 103234s5195sPI.pdf (accessed October 16, 2009).

-2 Henke M, Laszig R, Rube C, Schafer U, Haase K-D, Schlicher B, Mose S, Beer KT, Burger U, Dougherty C, Frommhold H: Erythropoietin to treat head and neck cancer patients with anaemia undergoing radiotherapy: randomised, double-blind, placebo-controlled trial. Lancet 2003;362:1255-1260.

-3 Leyland-Jones B, Semiglazov V, Pawlicki M, Pienkowski T, Tjulandin S, Manikhas G, Makhson A, Roth A, Dodwell D, Baselga J, Biakhov M, Valuckas K, Voznyi E, Liu X, Vercammen E: Maintaining normal hemoglobin levels with epoetin alfa in mainly nonanemic patients with metastatic breast cancer receiving first-line chemotherapy: a survival study. J Clin Oncol 2005;23:59605972.

- 4 Wright JR, Ung YC, Julian JA, Pritchard KI, Whelan TJ, Smith C, Szechtman B, Roa W, Mulroy L, Rudinskas L, Gagnon B, Okawara GS, Levine MN: Randomized, double-blind, placebo-controlled trial of erythropoietin in non-small-cell lung cancer with disease-related anemia. J Clin Oncol 2007;25:10271032 .

5 US Renal Data System. USRDS 2008 Annual Data Report: Atlas of Chronic Kidney Disease \& End-Stage Renal Disease in the United States. Bethesda, National Institutes of Health, National Institute of Diabetes and Digestive and Kidney Diseases, 2008.

6 US Department of Health and Human Services. End-Stage Renal Disease Medical Evidence Report Medicare Entitlement and/or Patient Registration: Form CMS-2728-U3. Centers for Medicare and Medicaid Services. June 1997. Available at: http://www.usrds. org/2008/rg/forms/02_2728_1965.pdf (accessed October 16, 2009).

7 US Department of Health and Human Services. End-Stage Renal Disease Medical Evidence Report Medicare Entitlement and/or Patient Registration: Form CMS-2728-U3. Centers for Medicare and Medicaid Services. June 2004. Available at: http://www.usrds. org/2008/rg/forms/03_2728_2005.pdf. 2004 (accessed October 16, 2009).

8 US Department of Health and Human Services. ESRD Death Notification: Form CMS2746-U3. Centers for Medicare and Medicaid Services. January 2004. Available at: http://www.usrds.org/2008/rg/forms/ 05_2746_Death_Notification_2004.pdf (accessed October 16, 2009).
-9 Bohlius J, Langensiepen S, Schwarzer G, Seidenfeld J, Piper M, Bennett C, Engert A: Recombinant human erythropoietin and overall survival in cancer patients: results of a comprehensive meta-analysis. J Natl Cancer Inst 2005;97:489-498.

10 Boogaerts M, Oberhoff C, Ten Bokkel HW, Nowrousian MR, Hayward CR, Burger HU: Epoetin- $\beta$ (NeoRecormon) therapy in patients with solid tumours receiving platinum and non-platinum chemotherapy: a metaanalysis. Anticancer Res 2006;26:479-484.

11 Bohlius J, Wilson J, Seidenfeld J, Piper M, Schwarzer G, Sandercock J, Trelle S, Weingart O, Bayliss S, Brunskill S, Djulbegovic B, Benett CL, Langensiepen S, Hyde C, Engert E: Erythropoietin or darbepoetin for patients with cancer. Cochrane Database Syst Rev 2006;3:CD003407.

12 Ross SD, Allen IE, Henry DH, Seaman C, Sercus B, Goodnough LT: Clinical benefits and risks associated with epoetin and darbepoetin in patients with chemotherapy-induced anemia: a systematic review of the literature. Clin Ther 2006;28:801-831.

13 Aapro M, Coiffier B, Dunst J, Osterborg A, Burger HU: Effect of treatment with epoetin$\beta$ on short-term tumour progression and survival in anaemic patients with cancer: a meta-analysis. Br J Cancer 2006;95:14671473.

14 Wilson J, Yao GL, Raftery J, Bohlius J, Brunskill S, Sandercock J, Bayliss S, Moss P, Stanworth S, Hyde C: A systematic review and economic evaluation of epoetin- $\alpha$, epoetin- $\beta$ and darbepoetin- $\alpha$ in anaemia associated with cancer, especially that attributable to cancer treatment. Health Technol Assess 2007;11:1-iv.

15 Bennett CL, Silver SM, Djulbegovic B, Samaras AT, Blau CA, Gleason KJ, Barnato SE, Elverman KM, Courtney DM, McKoy JM, Edwards BJ, Tigue CC, Raisch DW, Yarnold PR, Dorr DA, Kuzel TM, Tallman MS, Trifilio SM, West DP, Lai SY, Henke M: Venous thromboembolism and mortality associated with recombinant erythropoietin and darbepoetin administration for the treatment of cancer-associated anemia. JAMA 2008;299: 914-924.

16 Aapro M, Scherhag A, Burger HU: Effect of treatment with epoetin- $\beta$ on survival, tumour progression and thromboembolic events in patients with cancer: an updated meta-analysis of 12 randomised controlled studies including 2,301 patients. Br J Cancer 2008;99:14-22.
17 Bohlius J, Schmidlin K, Brillant C, Schwarzer G, Trelle S, Seidenfeld J, Zwahlen M, Clarke M, Weingart O, Kluge S, Piper M, Rades D, Steensma DP, Djulbegovic B, Fey MF, Ray-Coquard I, Machtay M, Moebus V, Thomas G, Untch M, Schumacher M, Egger $M$, Engert A: Recombinant human erythropoiesis-stimulating agents and mortality in patients with cancer: a meta-analysis of randomised trials. Lancet 2009;373:1532-1542.

18 Bohlius J, Wilson J, Seidenfeld J, Piper M, Schwarzer G, Sandercock J, Trelle S, Weingart O, Bayliss S, Djulbegovic B, Bennett CL, Langensiepen S, Hyde C, Engert A: Recombinant human erythropoietins and cancer patients: updated meta-analysis of 57 studies including 9,353 patients. J Natl Cancer Inst 2006;98:708-714

19 Silva M, Benito A, Sanz C, Prosper F, Ekhterae D, Nunez G, Fernandez-Luna JL: Erythropoietin can induce the expression of bcl-x $(\mathrm{L})$ through Stat5 in erythropoietin-dependent progenitor cell lines. J Biol Chem 1999;274:22165-22169.

-20 Kashii Y, Uchida M, Kirito K, Tanaka M, Nishijima K, Toshima M, Ando T, Koizumi K, Endoh T, Sawada K, Momoi M, Miura Y, Ozawa K, Komatsu N: A member of Forkhead family transcription factor, FKHRL1, is one of the downstream molecules of phosphatidylinositol 3-kinase-Akt activation pathway in erythropoietin signal transduction. Blood 2000;96:941-949.

-21 Digicaylioglu M, Lipton SA: Erythropoietinmediated neuroprotection involves crosstalk between Jak 2 and NF- $\mathrm{KB}$ signalling cascades. Nature 2001;412:641-647.

-22 Yang CW, Li C, Jung JY, Shin SJ, Choi BS, Lim SW, Sun BK, Kim YS, Kim J, Chang YS, Bang BK: Preconditioning with erythropoietin protects against subsequent ischemiareperfusion injury in rat kidney. FASEB J 2003; 17:1754-1755

23 Foley RN, Chen SC, Collins AC: Hemodialysis access at initiation in the US, 2005-2007: still 'catheter first'. Hemodial Int 2009;13: 533-542.

24 Stewart JH, Buccianti G, Agodoa L, Gellert R, McCredie MR, Lowenfels AB, Disney AP, Wolfe RA, Boyle P, Maisonneuve P: Cancers of the kidney and urinary tract in patients on dialysis for end-stage renal disease: analysis of data from the United States, Europe, and Australia and New Zealand. J Am Soc Nephrol 2003;14:197-207.

25 Rocco MV, Yan G, Gassman J, Lewis JB, Ornt D, Weiss B, Levey AS: Comparison of causes of death using HEMO Study and HCFA endstage renal disease death notification classification systems. The National Institutes of Health-funded Hemodialysis. Health Care Financing Administration. Am J Kidney Dis 2002;39:146-153. 